\title{
A 40-year-old Woman with Hypercalcemia Crisis Caused by Bone Metastasis in Stage IV Breast Cancer
}

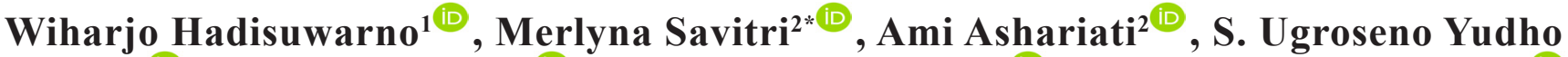 \\ Bintoro $^{2 \oplus}$, M. Noor Diansyah ${ }^{2}$, Putu Niken Ayu Amrita $^{2 \oplus}$, Pradana Zaky Romadhon ${ }^{2}$
}

${ }^{1}$ Department of Internal Medicine, Faculty of Medicine, Universitas Airlangga - Dr. Soetomo General Academic Hospital, Surabaya, Indonesia

${ }^{2}$ Medical Hematology Oncology Division, Department of Internal Medicine, Faculty of Medicine, Universitas Airlangga Dr. Soetomo General Academic Hospital Surabaya, Indonesia

\section{A R T I C L E I N F O}

\section{Article history:}

Received 19 August 2021

Received in revised form 1

September 2021

Accepted 10 October 2021

Available online 31 October 2021

\section{Keywords:}

Breast cancer,

Bone metastasis,

Hypercalcemia crisis.

*) Corresponding author:

merlyna.savitri@gmail.com

\begin{abstract}
A B S T R A C T
Breast cancer is still global burden especially for woman with 2.3 million cases every year dan $15 \%$ mortality among cancer diseases. In developing countries, most of the cases are diagnosed at terminal stage when metastasis already found. Bone metastasis is the highest among other metastasis sites such as: lung, liver and brain. Bone metastasis will cause hypercalcemia and bone pain as complications. Both will gradually decrease patient's quality of life. Comprehensive and holistic management for these complications will reduce deterioration and hopefully increase patient's quality of life even they were at terminal stage. We describe a 40-year-old woman who got hypercalcemia crisis. Hypercalcemia usually manifest as a consequence of other diseases. Epidemiologically, majority come from metastasis, but can be other diseases, such as multiple myeloma. Interestingly, during medical investigation through her medical history, and physical examination, and laboratory examinations, we conclude that her hypercalcemia crisis was caused by bone metastasis from breast cancer.
\end{abstract}

\section{Introduction}

Breast cancer, malignancy that attacks breast tissue, is a result of the interaction between host and environmental factors. ${ }^{1}$ In Indonesia, breast cancer is the most common cancer for women in 2020 both in new cases and mortality. ${ }^{2}$ Most cases in developing countries are found in late stage when metastasis already found. The most common sites of metastasis are bone, lung and liver. ${ }^{3}$ The prevalence of bone metastases ranks first in the number of breast cancer metastases. As a result of bone metastases, there will be a dominant osteolytic activity which results in the release of calcium in the blood causing hypercalcemia. ${ }^{4}$ In breast cancer, hypercalcemia is reported to occur in $30-40 \%$ of cases. ${ }^{5}$ Because some manifestations can mimic another disease, it is important to diagnose both clinical and additional examination. This case report will show the case of a woman with bone metastatic breast cancer with hypercalcemia due to extensive osteolytic.

Case
A 40 -Year-old woman came with bone pain around back
area in the past 4 months ago and worsen. Radiating pain to
both legs made her mobility gradually decreased and weak.
She reported a $5 \mathrm{~kg}$ intentional weight loss over 2 months.
One-week prior admission she could not eat because
of nausea and vomiting. She also complained about
unspecific chest pain at her left and right ribs, headache.
Sometimes, she felt hard to breathe because of the pain
around her rib. Her past medical history was painless breast
lump for 15 years, uncontrolled hypertension, no diabetes
and no history of other malignancies. Her social history:
hormonal contraceptive injection more than 10 years, often
consume pain reliever pills. She works as a laborer in local
factory (cooking section). Physical examination: patient
was alert with blood pressure $130 / 82$ mmHg, heart rate
87 times per minute, respiratory rate 20 times per minute,
axillar temperature $36.5^{\circ} \mathrm{C}$, oxygen saturation $96 \%$ with


nasal cannula, visual analog score was around 2. Head and neck examination revealed anemic conjunctiva, no enlargement lymph node. Local status at right breast area (Figure 1), inspection: nipple retraction and skin dimpling, palpation we found single $6 \mathrm{~cm}$ solid painless mass in the upper outer quadrant of the right breast (11 o'clock). From history taking and physical examination we suggest few additional examinations such as, laboratory, radiology, ultrasonography, Fine Needle Aspiration Biopsy (FNAB) and core biopsy. Initial blood test showed hemoglobin $11.4 \mathrm{~g} / \mathrm{dL}, \mathrm{MCV} 81.0 \mathrm{fl}, \mathrm{MCH} 25.9 \mathrm{pg}$, leukocytes 6110 cells/mm3, neutrophil 49\%, thrombocyte $169000 / \mathrm{uL}$, ESR $75 \mathrm{~mm} / \mathrm{h}$, Calcium $14.2 \mathrm{mg} / \mathrm{dL}$, Potassium $2.6 \mathrm{mmol} / \mathrm{L}$. Creatinine serum $1.5 \mathrm{mg} / \mathrm{dL}$, bone survey shows multiple osteolytic at skull, scapulae, humerus, right and left 1st -12th costae, corpus vertebrae, and right and left pelvic, femur bone, indicated as metastasis process or multiple myeloma (Figure 2). On day 3, patient still complain about bone pain. Blood test revealed Calcium $12.3 \mathrm{mg} /$ dl., Albumin $2.7 \mathrm{~g} / \mathrm{dL}$ (Calcium Corrected $13.04 \mathrm{mg}$ / dl), Ca 15-3 119.9 u/ml, Magnesium $1.3 \mathrm{mg} / \mathrm{dL}$. Protein electrophoresis: Albumin and Beta globulin fraction decrease, and Alpha-1 and gamma globulin increase. Her protein electrophoresis result exclude the multiple myeloma diagnosis. Ultrasonography (Figure 3) revealed heteroechoic solid mass skin $6.0 \times 4.8 \times 1.7 \mathrm{~cm}$ at right upper quadrant breast, unspecified bilateral axilla enlargement. Patient was given crystalloid up to $3000 \mathrm{ml}$ per day, with Dexamethasone injection. On day 5 patient felt that her bone pain worse with VAS 4-6, and dyspnea. Chest X-ray (Figure 4) showed infiltrate at right paracardial, indicated as metastasis process or pulmonary infection, multiple lytic lesions at right and left costa I-XII, clavicula bone, scapula bone and corpus vertebrae indicated as metastasis process, heart within normal limit. FNAB was performed and the result was ductal carcinoma in situ. Core Biopsy wasn't performed due to early pandemic situation, the facility didn't provide it for that moment. Patient was given zometa $4 \mathrm{mg}$ and tramadol $100 \mathrm{mg}$ intravenous, one-week later bone pain relieved, with calcium level decreased to $8.5 \mathrm{mg} / \mathrm{dl}$, creatinine serum $0.9 \mathrm{mg} / \mathrm{dL}$. Final assessment for this case was Stage IV breast cancer with bone and lung metastasis, post hypercalcemia, hypochromic microcytic anemia malignancy related, acute kidney injury, hypoalbuminemia, hypo magnesium, grade I hypertension JNC VII, cancer pain. Patient was discharged from hospital and referred to palliative care treatment.
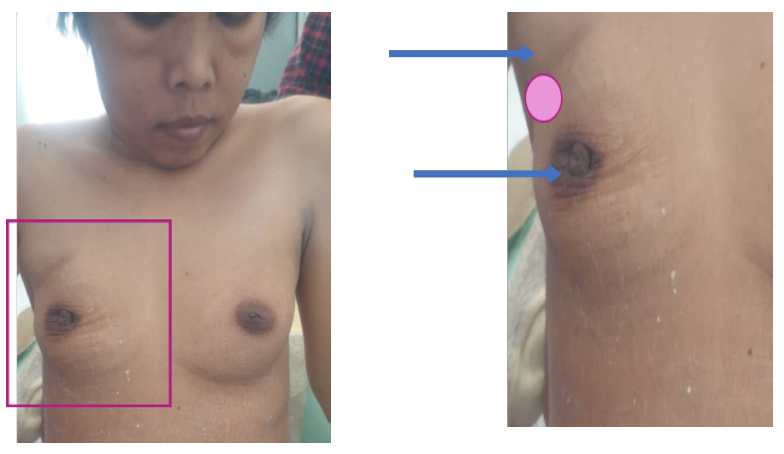

Figure 1. Breast Local status revealed painless palpable solid mass at 11 o'clock, diameter $6 \mathrm{~cm}$, mobile (+)
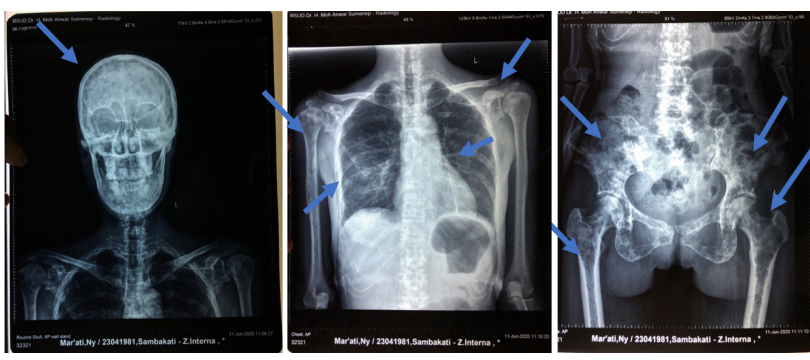

Figure 2. Bone survey indicated as metastasis process or multiple myeloma

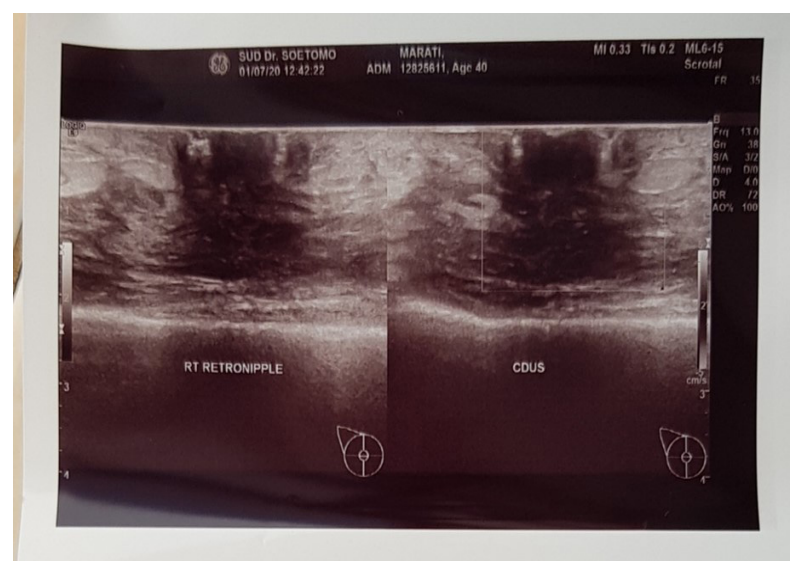

Figure 3. Breast Ultrasonography revealed heteroechoic solid mass at right upper quadrant breast, unspecified bilateral axilla enlargement

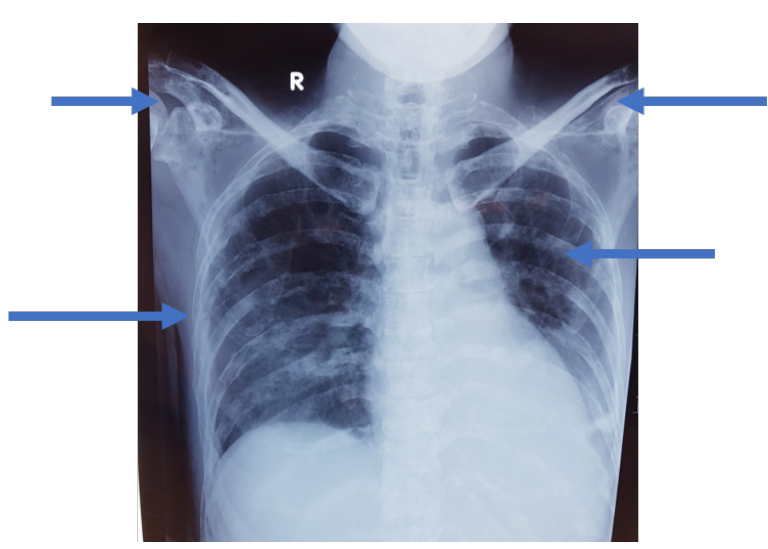

Figure 4. Indicated as metastasis process or pulmonary infection

\section{Discussion}

Breast cancer still lead the top mortality cause among other cancer form especially in women. All cancer disease should be diagnosed by triple diagnosis. Three combination modalities from physical examination, imaging (USG or Mammography) and cytology (FNAB and core biopsy) will increase more accurate result than one modality. ${ }^{6}$ A study in India showed that the most common location for breast lump at outer upper quadrant (29.2\%), and approximately 31.7\% were suspected malignant. That study also revealed that $65 \%$ of breast lump still mobile. ${ }^{7}$ In this patient we did all three modalities from physical examination we found breast lump, then we continue to USG, and we got ductal carcinoma in situ from FNAB. Generally, 
breast cancer management have some modalities from surgery, radiation, systemic chemotherapy and targeted therapy. Local therapy includes surgery, ablation and radiation. Systemic therapy includes chemotherapy, hormonal therapy, and targeted therapy. ${ }^{8}$ Breast cancer management also have some focus on therapy whether for curative or palliative care. Curative therapy focuses for early breast cancer without metastasis process. Palliative therapy focuses on cancer pain management, control metastasis symptom, holistic management include psychosocial and spiritual for patient. ${ }^{9}$ Patient also complain about her pain around her back. Using WHO Guideline for cancer pain management, we evaluate pain location, determine the Visual Analog Scale (VAS) Score and start the treatment. In the end, her pain relieved.

Bone is the most common site for breast cancer metastasis, followed by lung, liver, pleura. ${ }^{10}$ Bone metastasis significantly reduce 5-year survival rate and made serious complication. Osteodynia and nerve compression will also decrease patient's quality of life. ${ }^{11}$ As a result, osteolytic activity will become more dominant and will release calcium at blood circulation. In the end hypercalcemia occurred. Hypercalcemia divided into three degrees: mild, moderate and crisis. Mild hypercalcemia 10.5-11.9 $\mathrm{mg} / \mathrm{dL}$, moderate hypercalcemia 12.0-13.9 $\mathrm{mg} / \mathrm{dL}$ and hypercalcemia crisis 14.0-16.0 mg/dL.4 Hypercalcemia also used as an indicator to determine breast cancer progressivity. ${ }^{12}$ Hypercalcemia symptoms depend on the degree. Mild hypercalcemia sometimes asymptomatic while hypercalcemia crisis sometimes presents with symptoms. Gastrointestinal symptoms such as nausea, vomiting. Neuromuscular symptoms such as decrease of consciousness, impaired concentration. Musculoskeletal symptoms such as decrease mobility, bone pain, and weakness also present. ${ }^{13}$ Hypercalcemia management principle should base on patient sign, symptoms, hypercalcemia degrees, looking for the cause of hypercalcemia. ${ }^{14}$ Hypercalcemia crisis should be treated immediately and aggressively. The most effective and the safest treatment include rehydration using normal saline followed by diuretic agent, calcitonin and bisphosphonate. ${ }^{15}$ Normal saline can be given up to 1-2 liters for initiation followed by $100-150 \mathrm{ml}$ per hour as a maintenance. Patient without any comorbid can be given up to 4-6 liters intravenous fluid. ${ }^{16}$ Diuretic agent usually given for patient with cardiac and renal impairment because risk of hypervolemia. Diuretic administration should consider several risk factors such as electrolyte imbalance and hypovolemia risk. ${ }^{16}$ Glucocorticoid administration will also decrease calcium intestine absorption through blocked calcidiol become calcitriol and increase calcium excretion via urine. Hydrocortisone 200-400 mg/day for 3-5 days followed by oral prednisone 10-20 mg per day for 7 days can be given. Side effect such as hyperglycemia, electrolyte imbalance must be monitored. ${ }^{17}$ Patient was treated aggressively when admitted due to hypercalcemia crisis. We start giving normal saline up to 2 liters per day and monitor her urine production. Diuretic can be given when her volume status already euvolemic to prevent fluid loss in this patient. Electrolyte serum should be monitored during Diuretic administer to prevent another electrolyte imbalance.

Pain also matters for cancer patient management. Important component for pain management such as: early initiation dan maintenance of painkiller, additional therapy also important. World Health Organization analgetic stepladder for cancer pain can be initiate with non-steroid anti inflammation drug, then combine with weak or strong opioid, or add several adjuvant therapies when necessary. Adjuvant therapies such as corticosteroid, antidepressant, anticonvulsant and bisphosphonate can be given at any stages. ${ }^{18}$ Bisphosphonate reduce osteoclast activity which give good effect for breast cancer patient. Skeletal Related Event such as compression fracture risk, pathologic fracture, spinal cord compression, and hypercalcemia also. ${ }^{19}$

\section{Conclusion}

A case of 40-year-old woman with hypercalcemia crisis caused by extensive osteolytic from bone metastasis. Hypercalcemia can be one sign of several diseases, such as malignancy or non-malignancy. The diagnosis of primary caused of hypercalcemia is still quite challenging Hypercalcemia crisis sign and symptom can be seen at the whole-body systems. As an emergency cases, hypercalcemia crisis must be treated immediately, through some modalities as explained before.

\section{Conflict of Interest}

The author stated there is no conflict of interest

\section{References}

1. Nickels S, Truong T, Hein R, Stevens K, Buck K, Behrens S, Eilber $\mathrm{U}$, Schmidt $\mathrm{M}$, et al.Evidence of gene-environment interactions between common breast cancer susceptibility loci and established environmental risk factors. PLoS Genet.2013;9(3): 1-14

2. Global Burden of Cancer Study, 2020. Global cancer Observatory: Indonesia. Globocan

3. Chen MT, Sun HF, Zhao Y, Fu WY, Yang LP, Gao SP, Li LD, Jiang HL, Jin W. Comparison of patterns and prognosis among distant metastatic breast cancer patients by age groups: a SEER populationbased analysis. Scientific Reports.2017;7(1):9254: 1-8

4. Shane E, Irani D, 2006. Hypercalcemia: Pathogenesis, clinical manifestations, differential diagnosis, and management. In: Primer on the Metabolic Bone Diseases and Disorders of Mineral Metabolism, 6, Favus MJ (Ed), American Society for Bone and Mineral Research, Washington, DC

5. Michels KB, Xue F, Brandt L, et al. Hyperparathyroidism and subsequent incidence of breast cancer. Int J Cancer.2004;110: 449-51

6. Karim MO, Khan KA, Khan AJ, Javed A, Fazid S, Aslam MI.Triple Assessment of Breast Lump: Should We Perform Core Biopsy for Every Patient? Cureus.2020;12(3):e7479.

7. Ravi C, Rodrigues G. Accuracy of clinical examination of breast lumps in detecting malignancy: a retrospective study. Indian J Surg Oncol.2012;3(2):154-7

8. National Cancer Comphrehensive Network.2020. NCNN Clinical Practice Guidelines in oncology (NCNN Guidelines) for Breast Cancer. NCNN Foundation

9. Mutebi M, Anderson BO, Duggan C, Adebamowo C, Agarwal G, Ali Z, Bird P, Bourque JM, DeBoer R, Gebrim LH, Masetti R, Masood S, Menon M, Nakigudde G, Ng'ang'a A, Niyonzima N, Rositch AF, Unger-Saldaña K, Villarreal-Garza C, Dvaladze A, El Saghir NS, Gralow JR, Eniu A. Breast cancer treatment: A phased approach to implementation. Cancer.2020;126 (10):2365-78

10. Irvin W Jr, Muss HB, Mayer DK. Symptom management in metastatic breast cancer. Oncologist.2011;16(9):1203-14

11. Xiong Z, Deng G, Huang X, Li X, Xie X, Wang J, Shuang Z, Wang $\mathrm{X}$. Bone metastasis pattern in initial metastatic breast cancer: a population-based study. Cancer Manag Res.2018;10:287-295. 
12. Sigvaldason H, Obayan A, von Kuster K, Pathak KA. Hypercalcemia in metastatic breast cancer unrelated to skeletal metastasis. CMAJ.2016;188(5):E91-E94

13. Carroll MF, Schade DS. A practical approach to hypercalcemia. Am Fam Physician.2003;67(9):1959-66.

14. Crowley R, Gittoes N. How to approach hypercalcaemia. Clin Med (Lond).2013;13(3):287-90

15. Ziegler R. Hypercalcemic crisis. J Am Soc Nephrol.2011;12(suppl 17):S3-9

16. LeGrand SB, Leskuski D, Zama I. Narrative review: furosemide for hypercalcemia: an unproven yet common practice. Ann Intern Med. 2008;149(4):259-63

17. Sternlicht, H., \& Glezerman, I. G. (2015). Hypercalcemia of malignancy and new treatment options. Therapeutics and clinical risk management.2015;11:1779-88.

18. World Health Organization, 2018. WHO guidelines for the pharmacological and radiotherapeutic management of cancer pain in adults and adolescents. World Health Organization

19. Goldvaser H, Amir E. Role of Bisphosphonates in Breast Cancer Therapy. Curr Treat Options Oncol.2019;20(4):26 